\title{
Research on Teaching Reform of Clothing Structure Design in Intelligent Era
}

\author{
Boqi Tang \\ Jiang xi Institute of Fashion Technology \\ Jiang xi, Nanchang, China 330201
}

\begin{abstract}
In nowadays, computer assistance has developed into normalization, automation, intelligence and network in our social activities and since the establishment of CAD and CAM system, computer-assisted costume designing has been widely recognized by costume industry, due to the rapid development of intelligence and network, resulting in sharp increasing of talents demand in costume industry. In order to meet the lack of talents in costume industry demanded in socialized development, the fashion design education should advance with the times to cultivate talents of higher education, proficient and top in academic. In this article, the writer, by virtue of years of experience inclothing structure design and going through the change from pure manual plate-making to computer-assisted plate-making, puts forwards many thoughts on teaching reform to change the traditional ideas in aspects of transformation of teaching thought, improvement of teaching equipments, teaching sites advanced with times as well as market-oriented teaching achievements, based on costume structure practical education, so as to connect education and market closely, shorten the time of talent cultivation as well as reduce the training cost.
\end{abstract} reform

Keywords-intelligence; clothing structure design; teaching

\section{INTRODUCTION}

In the wake of rapid development of electronics technology and computer, a series of computer derivative systems in favor of convenient life are established, which also make great contribution in costume industry. As one of the lifelines of modern economic development, the costume has extended to rings of costume design and with the fast development of computer-assisted costume design $R \& D$ system in recent decades, in particular with the application of CAD and CAM, it opens the door to automation design, since when costume designs has sprung up like mushrooms. In nowadays, the universal application of computer to modern society has been normalization, relatively the social life turns to intelligent direction gradually as well as the costume industry opens the door to intelligence and network, which requires amounts of practitioners of costume high-technology and in order to cultivate more talents for close combination with market, lots of reform thoughts have been put forwards by specialists and scholars in costume industry and in certain scope, costume education has improved in some degree. However, as we know, the development of economy is so fast that the talents under the current costume education seem to be helpless confronting the development of intelligence. Hence, in order to meet the development of intelligence, advance with times and lead the future, reform and innovation of education are appealed for by the practitioners and participants in costume industry.

The writer, as a costume educator, has engaged inclothing structure design for years and put forwards lots of reform thoughts on teachingclothing structure design course, on bas is of conclusion of disadvantages of costume physical teaching in his teaching experience at frontline combined with the over-all situation of market. View points of the writer: transformation on teaching thoughts that to cultivate society-oriented talents; teaching site should not be limited to school that factory and other places in favor of teaching are also allowed; the teaching equipments should be actively operated that make the students participate in the actual producing process; and the process of teaching simulation also can be the process of production which can combine with the market and participate in the research and development of production in market so as to promote the students' enthusiasm etc. In the opinions of the writer, in case of the realization of mentioned aspects in teaching reform, the zero-distance connection between costume education and market will be completely reached in the future.

\section{TRANSFORMAT ION ON TEACHING THOUGHTS}

Mounts of practical operations exist in costume design teaching, which distinguishes costume education from other pure theory education and not only grasping theoretical knowledge is important, but also practice exercise is the best expression of teaching achievement, so that the thoughts of costume teaching is different from the education model of other major in certain degree. In process of costume structure design course, practice is more important than theory that structure drawing and analysis on pattern should be paid more attention during learning, while with respect to the traditional teaching method of demonstration on blackboard that the teacher follows regular procedures and students make structure design records with proportion of 1:5, and later draw actual costume structure pattern in pattern room according to the teaching process, may enhance the students' memory of pattern in some degree and strengthen their structure knowledge system, however, with the application of costume CAD, there are more and more problems exposed in tradition structure teaching. And costume CAD is successively used in assisting the completion of structure pattern design by virtue of the application of new technology and shortens the costume 
producing process in great degree. In nowadays, popularizing rate of computer assistance in modern enterprise has been up to $40 \%$ and much higher for developed countries so that the demand for computer-assisted operation application has became more and more important to enterprises and pushes the transformation of teaching thoughts, such as the erection of computer equipments and import of Lectra, A xe, Richpeace and other assistant costume design, since then new design thoughts are brought forclothing structure design, which becomes the first big transformation of thought on computerassistedclothing structure design teaching.

Along with the popularity of computer and development of network, in modern society, the slogan of intelligence-assisted costume design has become louder so that the teaching thoughts are ready for change as well under that slogan and from above we can know that intelligence of costume is no longer far from our life according to the current developing speed of modern economy. On the basis of first transformation, the costume structure design, as a very important course module of costume education, transfers faster in intelligent thought that $3 \mathrm{D}$ body measuring realizes body measuring automation, in which field many colleges have their actual teaching practices and make lots of research achievements; 3D draping design involving in the establishment of virtual modeling knowledge, simulates the draping course on computer and realizes the fashion design; the 3D virtual fit crossing thought limit, simulates actual action of human and animals and examines the rationality of design on costume structure by bringing wearing experience for virtual costume. For this time, the big transformation of thought changes the structure design course system. Many experts predicts that with the combination of mature use of 3D print technology and intelligence of costume, everyone can design their own costume and everyone can be costume designer.

\section{IMPROVEMENT OF TEACHING EQUIPMENT}

The current teaching system of costume structure design is still in accordance with traditional teaching model requiring the combination of theory lecture in classroom and practical operation in workshop, computer-assisted structure design and software application study, which teaching processes should be accomplished with the assistance of teaching equipments. For better application of computer-assisted design, the integration of hardware and software are needed, which requires a great amount of investment as well. Some of colleges with strong strength may invest a large amount of money on building teaching facilities, even part of them can on a regular basis to maintain the teaching equipments, upgrade teaching hardware and software, which expresses their responsibility to students and gratitude to society while with respect to integrated teaching institutions, it may beyond the reach of their ability.

Computer has popularized the modern society in high degree and it goes without saying of the investment in computer in aspect of costume structure design teaching, however, new type teaching software should be inspected before its introduction, since through some of the software is mature in application, it may not connect with production link of the enterprise, even has negative influence on production cost of enterprise and is unrealistic that can only stay in research phase. Currently, many enterprises are using Richpease software, which has powerful function and is easy to use, so that lots of colleges offer Richpease structure design course, to realize zero-distance connection with enterprise. The writer has visited mounts of colleges, which would like to introduce equipments in alternative to improve teaching equipment instead of refusing to invest equipments. Many of them prefer to let students practice in enterprise, due to consideration of usage rate of equipments and actual operation cost. In recent time, 3D print machine is hot in domestic due to its simplification on teaching links, however it has higher maintenance cost and repair rate correspondingly, which is also the reason many colleges would not like to introduce in nowadays. The writer believes that, based on common effort of society and colleges, advanced teaching hardware and software can be experienced in teaching constitution one day in the future.

\section{TEACHING SITE AND Sit UATIONAL TEACHING}

Many course systems are relative to course design of costume structure design, directly involving costume type design, costume technology and ready-made costume modeling, so that any link failure may result in subversive design of costume and in order to guarantee the quality of each link, in the writer's opinion, it is required to improve teaching means. Although intelligence may not be realized in college, it is necessary to make scientific planning and as a transitional link, costume design should do its best to meet the basic teaching requirements, adopting situational teaching model, combining teaching theory and practical teaching site, adding processing equipment for structure reasonability inspection as well as model exhibition for increasing visual effect into teaching process, by which case, it connects the structure design process and final exhibiting expression, mutually verified and making for the improvement of design content.

For containing that amounts of equipments, a large workshop is necessary and it greatly distinguishes from the small room of traditional teaching, the structure course of which adopts the teaching process in order of: theory teaching pattern-making in classroom - making pattern in pattern room - costume CAD assisted structure design - CAD patternmaking and there may be a comparis on between two modes of technology production in later courses and much time are spent on the way to classroom due to dis persive distribution of teaching sites while situational teaching mode can help students with the centralization of teaching facilities on each aspect, which is in favor of centralized operation of each teaching links so as to promote students' enthusiasm on learning. There are differences between college education and enterprise operation, hence, structure design course should be not only limited to books or college while change teaching site to practice in enterprise or work with the cooperation of enterprise as well as feel the different pattern structures in each large terminal stores at different levels or brands are also good choices.

\section{MARKET-ORIENTED TEACHING ACHIEVEMENT}

In intelligent era, modernity, popularity and novelty as well as other characteristics are expressed by costume sufficiently 
and the production process of costume has trended to be intelligent that it requires more talents in knowledge system of high-education, proficient and top in academic instead of too much manpower or material resources. Costume design develops with the development of economy and politics, structure design course, as professional education teaching of costume design, correspondingly should not stay at basic costume structure education but to combine the current model in market and strengthen the production and analysis of fashion costume pattern based on basic structure. With the propose of strengthening students' learning interest on costume structure and checking teachers' teaching achievement as well as students' learning effect, the structure design course can closely combine the market and establish certain cooperative mechanism with enterprises on a regular bas is to provide them the latest structure pattern. Sales data of the enterprise is the best answer to whether the researchoriented patterns teaching in class have market consumption ability, by which way it can guarantee the leading status of teachers in teaching and market, but also promote their teaching enthusiasm by given certain returns in economy.

The students' thoughts are various that there are always students being adept in study and it is the best witness of zerodistance connecting between enterprises and school teaching to fasten on good-learners' achievements and understand the students' learning achievements in market language combining enterprise and market so as to provide talents of higher education, proficient and top in academic. In nowadays, many colleges start to conduct research cooperation with enterprises, through few cooperation on structure design, it will bring abundant achievements inevitably upon the entry point of cooperation opens.

Besides above view points, in opinions of the writer, it is necessary to strengthen the improvement of subjective consciousness for reform of costume design course in aspects of teaching model and political trend etc. the times step forwards so is our production life and as the advanced level, only closely follow market trend and along with economic \& market ways can education benefit the nation and people. Knowledge cannot progress without education while education cannot promote without knowledge deepening, so that it is necessary to improve the lagging situation and the writer wish the reform of costume structure design course can advance boldly by virtue of the development trend of intelligent times so as to provide more qualified teaching means for the courses, cultivate more research-oriented teachers and students with wide knowledge, taking the road of low-profile \& progress and fashion \& connotation.

\section{REFERENCES}

[1] Sun Yufang; Wu Hongfang. Research Situation on Costume Intelligent Technology [J]. Sichuan Silk, May 25, 2008

[2] Wang Hong. Intelligent Production of Costume: Take the Road of Innovation [J]. China Fiber Inspection, April 23, 2015.

[3] Zhang Hao; Liu Feng. The Latest Technology and Application of Intelligent Electronic Costume [J]. China Textile Leader, December 08, 2011.
[4] Wu Jie; Xiao Juxia; Wei Qufu. Views on Costume Development Trend From Intelligence [J]. China Textile Leader, October 8, 2009.2004-0220

[5] Zhou Lihua. Digital Technology - Inexorable Trend of Apparel Industry in 21th Cent ury. [J]. Shandong Textile Science \& Technology, February 20, 2004.

[6] Wu Lindi; Wang Jianwei; Hao Ming. Costume Intelligent Technology [J]. Shanghai Textile Science \& Technology, April 30, 2005.2015-11-05

[7] Wang Shaobo; Wang Junling; Ma Dali. Drive "Made in China" with Technical Innovation [J]. Textile Science Research, November 05, 2015. 